\title{
The Effect of Kidney Morcellation on Operative Time, Incision Complications, and Postoperative Analgesia after Laparoscopic Nephrectomy
}

\author{
Affonso H. Camargo, Jonathan N. Rubenstein, Brent D. Ershoff, Maxwell V. Meng, \\ Christopher J. Kane, Marshall L. Stoller \\ Department of Urology, University of California San Francisco, San Francisco, California, USA
}

\begin{abstract}
Introduction: Compare the outcomes between kidney morcellation and two types of open specimen extraction incisions, several covariates need to be taken into consideration that have not yet been studied.

Materials and Methods: We retrospectively reviewed 153 consecutive patients who underwent laparoscopic nephrectomy at our institution, 107 who underwent specimen morcellation and 46 with intact specimen removal, either those with connected port sites with a muscle-cutting incision and those with a remote, muscle-splitting incision. Operative time, postoperative analgesia requirements, and incisional complications were evaluated using univariate and multivariate analysis, comparing variables such as patient age, gender, body mass index (BMI), laterality, benign versus cancerous renal conditions, estimated blood loss, specimen weight, overall complications, and length of stay.

Results: There was no significant difference for operative time between the 2 treatment groups $(\mathrm{p}=0.65)$. Incision related complications occurred in 2 patients $(4.4 \%)$ from the intact specimen group but none in the morcellation group $(\mathrm{p}=0.03)$. Overall narcotic requirement was lower in patients with morcellated $(41 \mathrm{mg})$ compared to intact specimen retrieval $(66 \mathrm{mg})$ on univariate $(\mathrm{p}=0.03)$ and multivariate analysis $(\mathrm{p}=0.049)$. Upon further stratification, however, there was no significant difference in mean narcotic requirement between the morcellation and muscle-splitting incision subgroup $(\mathrm{p}=0.14)$.

Conclusion: Morcellation does not extend operative time, and is associated with significantly less postoperative pain compared to intact specimen retrieval overall, although this is not statistically significant if a remote, muscle-splitting incision is made. Morcellation markedly reduces the risk of incisional-related complications.
\end{abstract}

Key words: nephrectomy; laparoscopy; pain

Int Braz J Urol. 2006; 32: 273-80

\section{INTRODUCTION}

Since its first report in 1991 (1), laparoscopic nephrectomy has progressively gained acceptance among urologists (2-5). Steps within this procedure are continuously being evaluated and modified to achieve better outcomes. Although a variety of techniques and devices have been developed for specimen entrapment and retrieval (6,7), no consensus on the best method has been established, but rather the choice is likely surgeon dependent or unproved factors. Specimen morcellation is associated with a smaller incision, better cosmesis, and fewer incisionrelated complications than open specimen extraction 
incisions $(8,9)$, but is associated with a longer operative time with a controversial benefit in regard to pain control. Morcellating a specimen containing tumor is felt to make accurate pathologic staging more difficult, but this has not yet been proved to be clinically detrimental due to the development of better clinical staging due to higher resolution imaging tests $(10,11)$, and the application of nomograms and standardized protocols for pathologic evaluation of fragmented specimens (12). The potential increased risk of tumor spill and port-site metastasis after morcellation has yet to be proven clinically significant $(13,14)$.

Previous studies evaluating the effects of tissue morcellation on morbidity and life quality have not shown a statistically significant difference regarding postoperative pain, hospital stay and recovery period when compared to intact specimen removal $(15,16)$. Unfortunately, these studies did not take into consideration other variables that could potentially affect the relationship between morcellation and operative time and post-operative pain, such as age, sex, body mass index, benign versus malignant renal conditions and overall complications. Our objective was to more accurately assess and compare the operative time, analgesia requirements, incision related complications, and overall length of stay in patients with morcellated and intact specimen extraction by entering additional variables into the analysis.

\section{MATERIALS AND METHODS}

We retrospectively reviewed the charts of 153 consecutive patients who underwent transperitoneal, 4-port laparoscopic nephrectomy for benign or malignant disease at our institution from September 1999 through June 2004. Our technique for laparoscopic nephrectomy with the use of a blunt-tip, radial dilating trocar (Step®, US Surgical, Norwalk, CT) for all ports was published previously (17). We routinely infiltrated the peritoneum under the laparoscopic port site with $3 \mathrm{~mL}$ of $0.25 \%$ bupivacaine and the extraction incision (when used) with $10 \mathrm{~mL}$ of $0.25 \%$ bupivacaine. Patients who underwent hand- assisted nephrectomy, nephroureterectomy, donor nephrectomy, and cases requiring open conversion were excluded from the study. All specimens were placed within a medium or large size LapSac (Cook Urological, Spencer, IN) prior to specimen retrieval. All specimens could be placed within a medium or large LapSac.

In 107 patients the kidney specimen was morcellated, while 46 patients underwent intact specimen removal, either through a muscle-cutting incision connecting two port sites $(\mathrm{n}=16)$ or through a remote, muscle-splitting incision, either midline infra-umbilical or Pfannestiel incision $(n=30)$. For morcellated specimens, the mouth of the LapSac was pulled up through a port site that previously had a $12-\mathrm{mm}$ port, and ring forceps were used to extract pieces of the tissue until all was removed. For the open extractions, after making the incision into the peritoneum, the LapSac was grasped and removed with the specimen intact. The choice to morcellate or not and the type of incision chosen was made by the primary surgeon either at the time of surgery or in discussion with the patient preoperatively, and generally was based upon prior incisions and personal cosmetic concerns and not necessarily based upon kidney size or underlying pathology.

Operative times, analgesia requirements (morphine equivalents administered during the postoperative period), length of hospital stay, and postoperative complications (incision and nonincision related) were evaluated and compared to a number of variables, including age, gender, body mass index, type of renal pathology (malignant versus benign), estimated blood loss and specimen weight. The dosage of narcotics required during the postoperative hospital stay was converted to morphine sulfate equivalents using of an equianalgesic table (18). Univariate analysis and multivariate regression were performed for statistical evaluation and significance was defined as a $\mathrm{p}$ value $\leq 0.05$.

\section{RESULTS}

Patient demographics are presented in Table1. There was no significant difference in patient age, 
sex, and laterality. There was a significant difference in the type of renal pathology, as 28 of 107 (26\%) patients who underwent kidney morcellation had a benign pathology compared to only 3 of $46(6.5 \%)$ within the intact specimen group $(p=0.01)$. The benign pathology consisted of patients with xanthogranulomatous pyelonephritis, chronic pyelonephritis, ureteropelvic junction obstruction, severe renal artery stenosis, and kidney tuberculosis. Patients undergoing radical nephrectomy whose final pathology were oncocytoma or angiomyolipoma were considered pre-operatively to have a potentially malignant disease and were therefore included in the cancer group.

The results of the univariate analysis are shown in Table-2. There was no significant difference between the mean operative time of the morcellation group (255 $\mathrm{min}$ ) and the intact specimen group (247 $\min )(\mathrm{p}=0.65)$. No additional variables were significantly correlated to operative time, and thus a multivariate model was unnecessary. The postoperative length of stay was similar between the two groups: 2.1 and 2.3 days in the morcellated and non-morcellated groups respectively $(\mathrm{p}=0.53)$.

The complications are listed in Table- 3 . The purpose of the list of complications is to determine the potential effect of a surgical complication on operative time, length of stay, and analgesia requirement. There were 18 complications in the morcellated group and 4 in the intact group. Detailed analysis revealed that the complications were completely unrelated to the incision in all cases except for $2(4.4 \%)$ In contrast, there were no complications related to the specimen retrieval site in the morcellated group $(0 \% ; \mathrm{p}=0.03)$

Univariate analysis indicated the mean narcotic requirement differed between the treatment groups (41 and $66 \mathrm{mg}$ in the morcellated and nonmorcellated patients, respectively, $\mathrm{p}=0.03$ ). Regression revealed that age and length of stay were

Table 1 - Patient demographics.

\begin{tabular}{llll}
\hline Variables & $\begin{array}{c}\text { Morcellation } \\
(\mathbf{n = 1 0 7 )}\end{array}$ & $\begin{array}{c}\text { Intact Specimen } \\
(\mathbf{n = 4 6})\end{array}$ & p Value \\
\hline Mean age (years) & 60 (range 42- 79) & 57 (range 37 - 81) & 0.22 \\
Body mass index & 28 & 29 & 0.62 \\
Sex (male/female) & $65 / 42$ & $24 / 22$ & 0.32 \\
Laterality (right/left) & $49 / 58$ & $21 / 25$ & 0.99 \\
Type of renal pathology (benign/malignant) & $28 / 79$ & $3 / 43$ & 0.01 \\
Specimen weight (grams) & 397 (range 312 - 604) & $510($ range 298 - 680) & 0.10 \\
\hline
\end{tabular}

Table 2 - Univariate analysis of the morcellated and intact specimen retrieval groups.

\begin{tabular}{lccc}
\hline Variables & \multicolumn{1}{c}{$\begin{array}{c}\text { Morcellation } \\
(\mathbf{n = 1 0 7})\end{array}$} & $\begin{array}{c}\text { Intact Specimen } \\
(\mathbf{n = 4 6})\end{array}$ & p Value \\
\hline Operative time (minutes) & 255 (range 128 - 310) & 247 (range 134- 304) & 0.65 \\
Incision related complications & $0(0 \%)$ & $2(4 \%)$ & 0.03 \\
Mean morphine equivalents required (mg) & 41 66 & 0.03 \\
Length of stay (days) & 2.1 (range 1.2 - 5.0) & 2.3 (range 1.2 - 5.2) & 0.53 \\
\hline
\end{tabular}


Table 3 - Intraoperative and postoperative complications in the morcellated and intact specimen retrieval groups.

\begin{tabular}{|c|c|}
\hline Morcellation $(n=107)$ & Intact Specimen Retrieval $(n=46)$ \\
\hline $\begin{array}{l}\text { Intraoperative } \\
\text { Retroperitoneal bleeding ( } 3 \text { cases) } \\
\text { Diaphragmatic injury ( } 1 \text { case) } \\
\text { Liver injury during Veress needle ( } 1 \text { case) } \\
\text { Small bleeding renal artery stump ( } 1 \text { case) } \\
\text { Airway trauma during intubation ( } 1 \text { case) } \\
\text { Groin hematoma ( } 1 \text { case) }\end{array}$ & $\begin{array}{l}\text { Intraoperative } \\
\text { Bladder injury during specimen retrieval (1 case) }\end{array}$ \\
\hline $\begin{array}{l}\text { Postoperative } \\
\text { Right upper pulmonary lobe collapse ( } 1 \text { case) } \\
\text { Pulmonary embolism ( } 1 \text { case) } \\
\text { Pulmonary edema ( } 2 \text { cases }) \\
\text { Respiratory failure }(1 \text { case }) \\
\text { Myocardial Infarction ( } 1 \text { case) } \\
\text { Arrhythmia ( } 1 \text { case) } \\
\text { Superficial vein thrombosis ( } 1 \text { case) } \\
\text { Prolonged ileus }(1 \text { case) } \\
\text { Abdominal wall hematoma* }(1 \text { case })\end{array}$ & $\begin{array}{l}\text { Postoperative } \\
\text { Acute renal failure ( } 1 \text { case) } \\
\text { Incisional hernia/small bowel obstruction ( } 1 \text { case }) \\
\text { Dehiscence ( } 1 \text { case })\end{array}$ \\
\hline
\end{tabular}

*The abdominal wall hematoma was unrelated to the morcellated specimen retrieval site.

correlated with postoperative analgesia, with a higher average narcotic requirement associated with younger patients and a longer hospital stay. Multivariate analysis demonstrated that the effect of morcellation on postoperative analgesia remained significant between the treatment groups while controlling for significant covariates $(\mathrm{p}=0.049)$. After stratification of the intact specimen group, no significant difference in the average narcotic requirement was found between the muscle cutting $(79 \mathrm{mg}$ ) and musclesplitting incision $(61 \mathrm{mg})$ subgroups $(\mathrm{p}=0.60)$. The two subgroups were individually compared with the morcellated specimen group. Analysis revealed a difference in postoperative analgesia between the morcellated group and the muscle cutting subgroup $(\mathrm{p}=0.046$ and $\mathrm{p}=0.05$ for univariate and multivariate, respectively), however, no significant difference was found between morcellation and the muscle splitting patients $(\mathrm{p}=0.06$ and $\mathrm{p}=0.14$ for univariate and multivariate analysis, respectively).

\section{DISCUSSION}

The introduction of laparoscopic nephrectomy and kidney morcellation in 1991 (1) was responsible for a substantial reduction in postoperative pain, hospital stay, and for a shorter recovery period compared to standard nephrectomy $(5,6)$. Although the advantages of laparoscopic nephrectomy are widely recognized, the ideal method for specimen removal is ill defined. It remains controversial as to the true effect that specimen morcellation has on operative time, postoperative pain, and the accuracy of malignancy staging through pathologic evaluation $(15,16)$.

It has been argued that morcellation should not be undertaken in cases of nephrectomy for cancer as this inhibits accurate tumor staging. While traditional staging can clearly not be performed in a morcellated specimen, the clinical effect of this is unknown. An in vitro study on pathological validity 
of morcellated kidneys affected by renal tumors, including cases of perinephric fat invasion, revealed identical histology, grade, and stage when intact specimen evaluations were compared to a second analysis of the same specimens after morcellation (19). Additionally, advances in abdominal imaging tests $(10,11)$, and mathematical models developed to guide pathologic sampling and analysis of morcellated specimens (12) can substantially increase the reliability of diagnosis and staging of renal malignancies.

In regards to operative time, as shown by previous studies and confirmed by our analysis $(15,16)$, morcellation following laparoscopic nephrectomy is not associated with longer operative times when compared to intact specimen retrieval. While morcellation may be a time consuming procedure, especially in patients with history of recurrent urinary tract infections, xanthogranulomatous pyelonephritis, and/or renal scarring, this is clearly offset by the time required to open and close an additional incision. Additionally, conditions such as obesity and inadvertent injury of subcutaneous vessels during an incision may account for even longer operative times. In addition, many of the patients in the morcellated group underwent nephrectomy for xanthogranulomatous pyelonephritis, chronic pyelonephritis, tuberculosis, and other endstage kidney disorders, which caused the kidneys to have a severe scar around them, making surgery much more difficult and time consuming.

While the overall length of hospital stay was not statistically significantly different between the two groups, this was true despite the higher number of complications in the morcellated group that certainly led to longer hospital stays. This difference in complication rate in this review probably has a number of explanations including random chance. Certainly, the complex nature of many of the kidneys removed for non-cancerous causes, which compromised $36 \%$ of the morcellated group, could have contributed to the difference in complication rate. The only two incision-related complications were in the intact group.

Recent publications failed to prove the benefits of morcellation regarding postoperative pain intensity $(15,16)$. However, these studies did not consider the possible effects of other variables on postoperative pain. In our study, patient age and length of stay were strongly correlated to postoperative pain. To generate a nonbiased assessment of the effect of morcellation on narcotic requirement, we used a multivariate regression model. Analysis revealed that older patients required lower dosages of morphine for postoperative pain control. This fact is consistent with a number of studies that demonstrated an increased pain threshold in the elderly patients that is felt to be due to a variety of physiologic changes (20).

For further analysis, we divided the intact specimen retrieval group into those who underwent a muscle cutting (i.e. connecting two ports) compared to muscle splitting (i.e. Pfannenstiel, low midline, or Gibson-type) incision. When comparing the two subgroups of intact incisions, there was no significant difference between the narcotic requirements. When comparing the narcotic requirements of each subgroup separately to that of the morcellated group, while there was a statistically significant difference between the muscle cutting group and the morcellated group, this was not significantly different in the muscle splitting group. It seems likely therefore that postoperative pain following laparoscopic nephrectomy may not be influenced by a single variable but more likely by a combination of retrieval incision location and length.

A potential weakness of the study is the retrospective nature of the review. Therefore, certain information that could further give insight to better outcomes, such as the change in surgical and laparoscopic experience over time, an actual accurate measurement of incision length, true analog pain scale results, and accurate time to return to daily activities could not be entirely assessed and for this reason were not included. A prospective randomized trial with multivariate statistical analysis is mandatory to help even better define these conclusions.

\section{CONCLUSIONS}

Kidney morcellation after laparoscopic nephrectomy does not extend operative time and is 
associated with a lower rate of incision-related complications. Patients who underwent kidney morcellation had a significantly lower postoperative narcotic requirement when compared to those in the intact specimen retrieval group. However, the difference in the mean analgesia requirement was not statistically significant between the morcellated group and those with a remote, muscle-splitting incision. Postoperative analgesia is likely influenced by a combination of factors.

\section{CONFLICT OF INTEREST}

None declared.

\section{REFERENCES}

1. Clayman RV, Kavoussi LR, Soper NJ, Dierks SM, Meretyk S, Darcy MD, et al.: Laparoscopic nephrectomy: initial case report. J Urol. 1991; 146: 278-82.

2. Cadeddu JA, Ono Y, Clayman RV, Barrett PH, Janetschek G, Fentie DD, et al.: Laparoscopic nephrectomy for renal cell cancer: evaluation of efficacy and safety: a multicenter experience. Urology. 1998; 52: 773-7.

3. Portis AJ, Yan Y, Landman J, Chen C, Barrett PH, Fentie DD, et al.: Long-term followup after laparoscopic radical nephrectomy. J Urol. 2002; 167: 1257-62.

4. Shuford MD, McDougall EM, Chang SS, LaFleur BJ, Smith JA Jr, Cookson MS: Complications of contemporary radical nephrectomy: comparison of open vs. laparoscopic approach. Urol Oncol. 2004; 22: 121-6.

5. Fornara $\mathrm{P}$, Zacharias $\mathrm{M}$, Steinacker $\mathrm{M}$, Doehn $\mathrm{C}$, Jocham D: Laparoscopic vs. open nephrectomy. 10 years' results of a nonrandomized comparative study of 549 patients with benign kidney diseases. Urologe A. 2003; 42: 197-204.

6. Sundaram CP, Ono Y, Landman J, Rehman J, Clayman RV: Hydrophilic guide wire technique to facilitate organ entrapment using a laparoscopic sack during laparoscopy. J Urol. 2002; 167: 1376-7.

7. Pautler SE, Harrington FS, McWilliams GW, Walther MM: A novel laparoscopic specimen entrapment device to facilitate morcellation of large renal tumors. Urology. 2002; 59: 591-3.

8. Shalhav AL, Leibovitch I, Lev R, Hoenig DM, Ramon $\mathrm{J}$ : Is laparoscopic radical nephrectomy with specimen morcellation acceptable cancer surgery? J Endourol. 1998; 12: 255-7.

9. Elashry OM, Giusti G, Nadler RB, McDougall EM, Clayman RV: Incisional hernia after laparoscopic nephrectomy with intact specimen removal: caveat emptor. J Urol. 1997; 158: 363-9.

10. Hallscheidt PJ, Bock M, Riedasch G, Zuna I, Schoenberg SO, Autschbach F, et al.: Diagnostic accuracy of staging renal cell carcinomas using multidetector-row computed tomography and magnetic resonance imaging: a prospective study with histopathologic correlation. J Comput Assist Tomogr. 2004; 28: 333-9.

11. Ergen FB, Hussain HK, Caoili EM, Korobkin M, Carlos RC, Weadock WJ, et al.: MRI for preoperative staging of renal cell carcinoma using the 1997 TNM classification: comparison with surgical and pathologic staging. AJR Am J Roentgenol. 2004; 182: 217-25.

12. Meng MV, Koppie TM, Stoller ML: Pathologic sampling of laparoscopically morcellated kidneys: a mathematical model. J Endourol. 2003;17: 22933.

13. Fentie DD, Barrett PH, Taranger LA: Metastatic renal cell cancer after laparoscopic radical nephrectomy: long-term follow-up. J Endourol. 2000; 14: 407-11.

14. Castilho LN, Fugita OE, Mitre AI, Arap S: Port site tumor recurrences of renal cell carcinoma after videolaparoscopic radical nephrectomy. J Urol. 2001; 165: 519.

15. Gettman MT, Napper C, Corwin TS, Cadeddu JA: Laparoscopic radical nephrectomy: prospective assessment of impact of intact versus fragmented specimen removal on postoperative quality of life. $\mathrm{J}$ Endourol. 2002; 16: 23-6.

16. Hernandez F, Rha KH, Pinto PA, Kim FJ, Klicos N, Chan TY, et al.: Laparoscopic nephrectomy: assessment of morcellation versus intact specimen extraction on postoperative status. J Urol. 2003; 170: 412-5.

17. Shekarriz B, Gholami SS, Rudnick DM, Duh QY, Stoller ML: Radially expanding laparoscopic access for renal/adrenal surgery. Urology. 2001; 58: 683-7.

18. Pereira J, Lawlor P, Vigano A, Dorgan M, Bruera E: Equianalgesic dose ratios for opioids. a critical review and proposals for long-term dosing. J Pain Symptom Manage. 2001; 22: 672-87. 
19. Landman J, Lento P, Hassen W, Unger P, Waterhouse R: Feasibility of pathological evaluation of morcellated kidneys after radical nephrectomy. J Urol. 2000; 164: 2086-9.
20. Gibson SJ, Farrell M: A review of age differences in the neurophysiology of nociception and the perceptual experience of pain. Clin J Pain. 2004; 20: 227-39.
Accepted after revision:

March 30, 2006

\section{Correspondence address:}

Dr. Marshall L. Stoller

Professor, Department of Urology

University of California, San Francisco

400 Parnassus Ave, Box 0718

San Francisco, 94143, CA, USA

Fax: + 415 353-2200

E-mail: mstoller@urol.ucsf.edu

\section{EDITORIAL COMMENT}

The present study approaches the fairly controversial area of specimen morcellation after laparoscopic nephrectomy, especially in malignant disease. Reviews of scientific literature reveal the many advantages of morcellation over intact removal, such as reduction of incision length with consequent reduced usage of postoperative analgesia, and shorter hospital stays (1); however, care must be taken with this technique in order to avoid sac perforation and possible subsequent dissemination of tumor cells within the abdominal cavity, as well as trocar site implantation (2-5) and inadvertent lesion of intraabdominal structures (6). Intact removal increases the size of the incision by $5-7 \mathrm{~cm}$ in those procedures considered minimally invasive, thus altering the aesthetic result and increasing postoperative pain (7). However, intact removal of the surgical specimen falls within the principles of oncologic surgery, thus reducing the risk of metastatic implants and aiding anatomical and pathological staging of the specimen
(8). Another relatively controversial aspect found in scientific reviews regards the amount of time necessary in morcellation of renal specimens, which some authors have reported as an average of 18 minutes (with durations varying from 6 to 34 minutes) (1); others claim an average time of 33 minutes (ranging from 18-115 minutes) (9).

The authors of the study in question have presented an excellent casuistry (153 laparoscopic nephrectomies) and have approached the main controversial aspects of morcellation, analyzing those variables, which may be related to operative time, postoperative analgesia, length of hospital stay, and complications associated with the incision.

It is a well-delineated retrospective study, which utilized a uniform methodology for the groups examined, with adequate statistical analysis of all variables involved (sex, age, body mass index, laterality, type of renal pathology, and weight of operative specimen). On the other hand, when the 
authors report the routine use of $0.25 \%$ bupivacaine for infiltration in incision and trocar sites, the amount of anesthetic used is not specified, and this may cause some alteration in the analysis of postoperative pain, as greater incisions will require a larger infiltration of local anesthetic.

The subject approached is controversial and sheds new perspectives in the field of specimen removal subsequent to laparoscopic nephrectomy, clarifying several myths about the prolonged time necessary for morcellation, as well as those regarding the risks inherent to the method.

\section{REFERENCES}

1. Landman J, Lento P, Hassen W, Unger P, Waterhouse R: Feasibility of pathological evaluation of morcellated kidneys after radical nephrectomy. J Urol. 2000; 164: 2086-9.

2. Castilho LN, Fugita OE, Mitre AI, Arap S: Port site tumor recurrences of renal cell carcinoma after videolaparoscopic radical nephrectomy. J Urol. 2001; 165: 519.
3. Tsivian A, Sidi AA: Port site metastases in urological laparoscopic surgery. J Urol. 2003; 169: 1213-8.

4. Meng MV, Miller TR, Cha I, Stoller ML: Cytology of morcellated renal specimens: significance in diagnosis and issemination. J Urol. 2003; 169: 45-8.

5. Fentie DD, Barrett PH, Taranger LA: Metastatic renal cell cancer after laparoscopic radical nephrectomy: long-term follow-up. J Endourol. 2000; 14: 407-11.

6. Landman J, Venkatesh R, Kibel A, Vanlangendonck $\mathrm{R}$ : Modified renal morcellation for renal cell carcinoma: laboratory experience and early clinical application. Urology. 2003; 62: 632-4; discussion 635 .

7. Gill IS: Laparoscopic radical nephrectomy for cancer. Urol Clin North Am. 2000; 27: 707-19.

8. Landman J, Lento P, Hassen W, Unger P, Waterhouse R: Feasibility of pathological evaluation of morcellated kidneys after radical nephrectomy. J Urol. 2000; 164: 2086-9.

9. Walther MM, Lyne JC, Libutti SK, Linehan WM: Laparoscopic cytoreductive nephrectomy as preparation for administration of systemic interleukin2 in the treatment of metastatic renal cell carcinoma: a pilot study. Urology. 1999; 53: 496-501.

\author{
Dr. Mardhen B. Araújo \\ Section of Urology \\ Federal University of Ceara \\ Fortaleza, Ceara, Brazil
}

